\title{
Reproduction and population dynamics of the solitary entoproct Loxosomella plakorticola inhabiting a demosponge, Plakortis sp.
}

\author{
Nagisa Sugiyama ${ }^{1}$, Tohru Iseto ${ }^{2,3}$, Mamiko Hirose ${ }^{1}$, Euichi Hirose ${ }^{1, *}$ \\ ${ }^{1}$ Faculty of Science, University of the Ryukyus, Senbaru, Nishihara, Okinawa 903-0213, Japan \\ ${ }^{2}$ Seto Marine Biological Laboratory, Field Science Education and Research Center, Kyoto University, Shirahama, Nishimuro, \\ Wakayama 649-2211, Japan \\ ${ }^{3}$ Present address: Japan Agency for Marine-Earth Science and Technology (JAMSTEC), Showa-machi, Kanazawa-ku, \\ Yokohama, Kanagawa, 236-0001, Japan
}

\begin{abstract}
Solitary entoprocts are sessile aquatic invertebrates inhabiting various non-living or living substrata. They proliferate through both sexual and asexual reproduction. However, fecundity and population dynamics of entoprocts are poorly understood, probably because the small size of the individuals ( 0.2 to $5 \mathrm{~mm}$ length) makes field studies difficult. To clarify the seasonal fluctuation of fecundity via sexual and asexual reproduction, we sampled the solitary entoproct Loxosomella plakorticola Iseto \& Sugiyama, 2008 (Entoprocta: Loxosomatidae) monthly over 2 yr. L. plakorticola often forms dense aggregates on a coral-reef demosponge, Plakortis sp. Budding occurred all year round and was most active from spring to early summer. There was a significant negative relationship between bud production and water temperature 2 mo previously. In contrast, sexual reproduction rarely occurred during our monitoring. Monthly monitoring of 4 sponges for 13 to 23 mo revealed that the density and distribution pattern of L. plakorticola on the sponges fluctuated highly regardless of season. Large populations sometimes disappeared from the host sponge within short periods, while, in other cases, a small, sparse population grew to a large, dense population within a few months. DNA sequencing analysis demonstrated that individuals on the same sponge did not belong to a single clone. Thus, the entoprocts probably disperse from one sponge to others. Populations on sponges were mainly formed and maintained by budding; sexual reproduction may contribute to longdistance dispersal and maintenance of genetic heterogeneity.
\end{abstract}

KEY WORDS: Budding $\cdot$ Reproductive strategy $\cdot$ Genetic heterogeneity $\cdot$ Coral reef $\cdot$ Kamptozoa

\section{INTRODUCTION}

Proliferation through both sexual and asexual reproduction is found in various taxa including sessile, aquatic invertebrates, such as cnidarians, bryozoans, or ascidians (Hughes \& Cancino 1985). It is understood that each organism or species makes trade-offs between sexual and asexual reproduction to enhance fitness through both modes of reproduction. In general, asexual reproduction is advantageous for rapid proliferation, while sexual reproduction is necessary to produce genetic heterogeneity and to disperse over large areas in many benthic, particularly sessile, organisms. However, many studies deal with relatively large, prominent organisms (Sebens 1981, 1982, Uthicke 1997, McGovern 2002), and the reproduction and population dynamics of sessile meiobenthic species is poorly understood. Meiobenthic organisms are often overlooked in the field because of their small ( 0.2 to $5 \mathrm{~mm}$ ), transparent bodies, however, they may be common species and have important functions in the marine ecosystem.

Entoprocts are colonial or solitary suspensionfeeders inhabiting marine environments, except for 2 
colonial species living in freshwater. They have been reported to occur over wide geographic areas from tropical to polar marine waters and from the intertidal to the deep sea. They live on various substrates, such as dead coral, shells, seaweed, or live animals, and most solitary species have been reported to associate with specific hosts, such as sponges, bryozoans, sipunculids, or polychaetes (Nielsen 1964). Benefits of commensal association include obtaining food and fresh water for respiration from water currents produced by the host (Nielsen 1964), and securing a safe habitat that protects the entoprocts from overgrowth by other fouling organisms and from predators (Iseto 2005). Entoprocts are very common. For instance, solitary entoprocts were shown to be the most dominant epizoans on glass slides submerged for 2 mo in the subtropical waters around Okinawa Island, Japan (Iseto et al. 2007).

Entoprocts reproduce both sexually and asexually. Asexual reproduction takes place through budding. Solitary species produce buds at a pair of laterofrontal or frontal areas of the calyx, and fully-grown buds are released from the adult individual. Liberated buds can swim slowly with their tentacle cilia (Atkins 1932, Nielsen 1989), but dispersal distance of liberated buds is unknown. By sexual reproduction entoprocts produce larvae. Solitary species are generally protandrous hermaphrodites, with a discrete male phase followed by a female phase (Nielsen 1971), while some dioecious species are known from colonial entoprocts (Wasson 1997). Following fertilization in ovaries, embryos are brooded in a deep depression at the calyx where they develop into trochophore-like larvae. The planktonic duration and dispersal distance of entoproct larvae is unknown. Adult individuals of some loxosomatid species can glide over, crawl on, detach from, and re-attach to the substratum with their foot (Iseto 2002, Iseto \& Hirose 2010). These locomotory abilities possibly contribute to population formation, although such abilities are unlikely to be suitable for long-distance dispersal.

There are many records of sexual and asexual reproduction in solitary entoprocts (summarized in Mariscal 1975, Nielsen 1989), but there are only a few reports based on annual monitoring. Quantitative sampling has hardly been carried out. Iseto et al. (2007) conducted monthly, quantitative surveys for $1 \mathrm{yr}$ on species composition, abundance, and reproduction in populations on glass slides that had been submerged for 2 mo at Okinawa Island, Japan. On the glass slides, 9 solitary species were found, and many individuals of them possessed buds. Sexual reproduction was restricted to a short period in summer (July to August) in 6 species, but was not found in the other species (Iseto et al. 2007). However, these results may not strictly reflect reproduction in natural populations, as artificial substrates were submerged for $2 \mathrm{mo}$, so the maximum age of examined entoprocts was $\leq 2$ mo.

Loxosomella plakorticola is a tiny solitary entoproct ( $\leq 1 \mathrm{~mm}$ long) and has a specific association with a coral-reef demosponge, Plakortis sp. (Iseto et al. 2008), where it often forms dense aggregates. This is the first quantitative survey on the seasonal fluctuation of reproduction of solitary entoprocts in natural conditions. If the occurrence of sexual reproduction is rare or exclusive in limited seasons in the natural population as observed in the population on the glass slides, we expect that the entoproct population is mainly established and maintained by asexual reproduction (= budding).

\section{MATERIALS AND METHODS}

Sampling. The solitary entoproct Loxosomella plakorticola inhabits the surface of a demosponge, Plakortis sp. This sponge species is common and prominent as reddish brown masses on the reef slope at 10 to $15 \mathrm{~m}$ depth off Manza (Okinwajima Island, Japan; $26^{\circ} 30^{\prime} 13.70^{\prime} \mathrm{N}, 127^{\circ} 50^{\prime} 32.39^{\prime} \mathrm{E}$ ). We performed monthly sampling of $L$. plakorticola over 2 yr. The host sponges (ca. $15 \mathrm{~cm}^{3}$ ) with entoprocts were collected by SCUBA diving from September 2006 to August 2008. They were narcotized by adding $0.37 \mathrm{M}$ $\mathrm{MgCl}_{2}$ up to an equal volume to the seawater immediately after collection, and then fixed with $2 \%$ formalin seawater. Some specimens were collected from two sponges (Sponge \#I, \#II) on October 10, 2009 at the same locality and preserved in $99.5 \%$ ethanol for DNA analyses.

Monitoring of the entoprocts on the host sponge. We also monitored the monthly density and distribution of entoprocts on 4 host sponges (Sponge \#1-4) for 13 to 23 mo to reveal the population dynamics of Loxosomella plakorticola on these hosts. L. plakorticola populations were labeled at the sampling site and photographed monthly with a $2 \times 2 \mathrm{~cm}$ grid placed above each sponge. The number of entoproct individuals in each grid was recorded in the following 4 categories: none, $<10,<100$, and $\geq 100$. The durations of monitoring were different among the labeled sponges: Sponges \#1 and \#2 (October 2006 to August 2008), \#3 (April 2007 to August 2008), and \#4 (September 2007 to August 2008). Monitoring could not be carried out in January 2007 due to strong waves.

Occurrence of sexual and asexual reproduction. From the specimens collected each month, 100 individuals were randomly selected to examine the presence or absence of buds and developing embryos under a stereoscopic microscope. Sexual reproduction was 
Table 1. Loxosomella plakorticola. PCR primers used for amplification and sequencing of ribosomal DNA

\begin{tabular}{|lll|}
\hline Primer & Primer sequence & Reference \\
\hline ss5 & GGTTGATCCTGCCAGTAGTCATATGCTTG & Rowan \& Powers (1991) \\
ss3 & GATCCTTCCGCAGGTTCACCTACGGAAACC & Rowan \& Powers (1991) \\
Lp18S-Fint1 & TGAACGACGAGGTAGTGACG & This study \\
Lp18S-Fint2 & TTACGTCCCTGCCCTTTGTA study \\
ITS5 & GGAAGTAAAAGTCGTAACAAGG & White et al. (1990) \\
ITS4 & TCCTCCGCTTATTGATATGC & White et al. (1990) \\
LpITS-Fint1 & CTCGTGGTGTACATGCTGCT & This study \\
LpITS-Rint1 & GGCAGCAAACAACAGACAAA & This study \\
LpITS1r & AGCAGCATGTACACCACGAG & This study \\
Lp5.8Sr & ACGTACGTTCCGAGTGATCC & This study \\
\hline
\end{tabular}

defined by the presence of developing embryo(s) in the brood pouch, and the number of embryos in each individual was recorded. Asexual reproduction was defined by the presence of bud(s) at the laterofrontal pockets of the calyx, and the number of buds on each individual was recorded. Even small swellings that represent early stage buds were counted.

Statistical analysis. Difference in number of buds in each individual between months (September 2006 to August 2007) was tested by Kruskal-Wallis test, and multiple comparisons were performed with Dunn's multiple comparisons test. Temporal trends of budding were compared with water temperature using crosscorrelation analysis. In this analysis, the Spearman's rank correlation coefficient was calculated with the number of budding individuals (or number of total buds in 100 individuals) lagging with respect to previous water temperature (time lag in months). Correlation at lag 0 was the usual Spearman's rank correlation. Correlation at lag 1 indicates the correlation of the number of budding individuals (or number of total buds in 100 individuals) with the water temperature from 1 mo previously. Similarly, correlations at lags 2, $3,4,5$, and 6 were calculated. We performed the analyses using InStat software (v. 3.1a, Graphpad Software, 2004).

Nucleotide sequencing. Genetic heterogeneity among entoproct individuals on the same sponge was demonstrated by comparing the nucleotide sequences of ribosomal DNA internal transcribed spacer 1 region (ITS1) of each individual. Individual Loxosomella plakorticola were picked up with tweezers from the sponge under a stereomicroscope. Selected specimens on the same sponge were at least $4 \mathrm{~mm}$ apart; generally, there were at least 7 individuals between selected specimens. Total genomic DNA was extracted using a ChargeSwitch gDNA Micro Tissue Kit (Invitrogen) following the manufacturer's protocol. Approximately 3500 base pairs of partial rDNA (18S rDNA (small ribosomal subunit DNA), ITS1 (internal transcribed spacer
1 region), 5.8S rDNA, and ITS2 (internal transcribed spacer 2 region)) were amplified using EX Taq polymerase (Takara) and a combination of the 'universal' primer ss5 (Rowan \& Powers 1991) and ITS4 (White et al. 1990). PCR amplification was performed under the following conditions: $94^{\circ} \mathrm{C}$ for $5 \mathrm{~min}$, followed by 40 cycles at $94^{\circ} \mathrm{C}$ for $1 \mathrm{~min}, 50^{\circ} \mathrm{C}$ for $1 \mathrm{~min}$, and $72^{\circ} \mathrm{C}$ for $4 \mathrm{~min}$, with final extension at $72^{\circ} \mathrm{C}$ for $7 \mathrm{~min}$. For defining the DNA sequences of the ITS rDNA region, intermediate primers were designed (Table 1). Prior to direct sequencing, amplification products were treated with ExoSAP-IT (GE Healthcare). Cycle sequencing reactions were performed using DTCS Quick Start Master Mix (Beckman Coulter), and the products were analyzed using a CEQ8800 (Beckman Coulter) automated DNA sequencing system.

In preliminary experiments, we found 3 variable sites over $550 \mathrm{bp}$ in length in the ITS1 region. In this study, ITS1 was amplified using combinations of the primers Lp18S-Fint1 and Lp5.8Sr (Table 1) for the test of clonality of Loxosomella plakorticola on a sponge. PCR amplification was performed under the following conditions: $94^{\circ} \mathrm{C}$ for $5 \mathrm{~min}$, followed by 35 cycles at $94^{\circ} \mathrm{C}$ for $1 \mathrm{~min}, 50^{\circ} \mathrm{C}$ for $1 \mathrm{~min}$, and $72^{\circ} \mathrm{C}$ for $2 \min 30 \mathrm{~s}$, with final extension at $72^{\circ} \mathrm{C}$ for $7 \mathrm{~min}$. Cycle sequencing reactions were then performed using combination of the primers ITS5 and LpITS1r (Table 1). The nucleotide sequences of the partial rDNA of L. plakorticola were deposited in Gen Bank/EMBL/DDBJ Accession Nos. AB560864 - AB560867.

\section{RESULTS}

\section{General morphology of Loxosomella plakorticola}

Dense populations of Loxosomella plakorticola ( $>100$ ind. $\mathrm{cm}^{-2}$ ) were often found on Plakortis sp. sponges (Fig. 1A,B), but not all sponges were infested. Other entoproct species were never found on Plakortis 

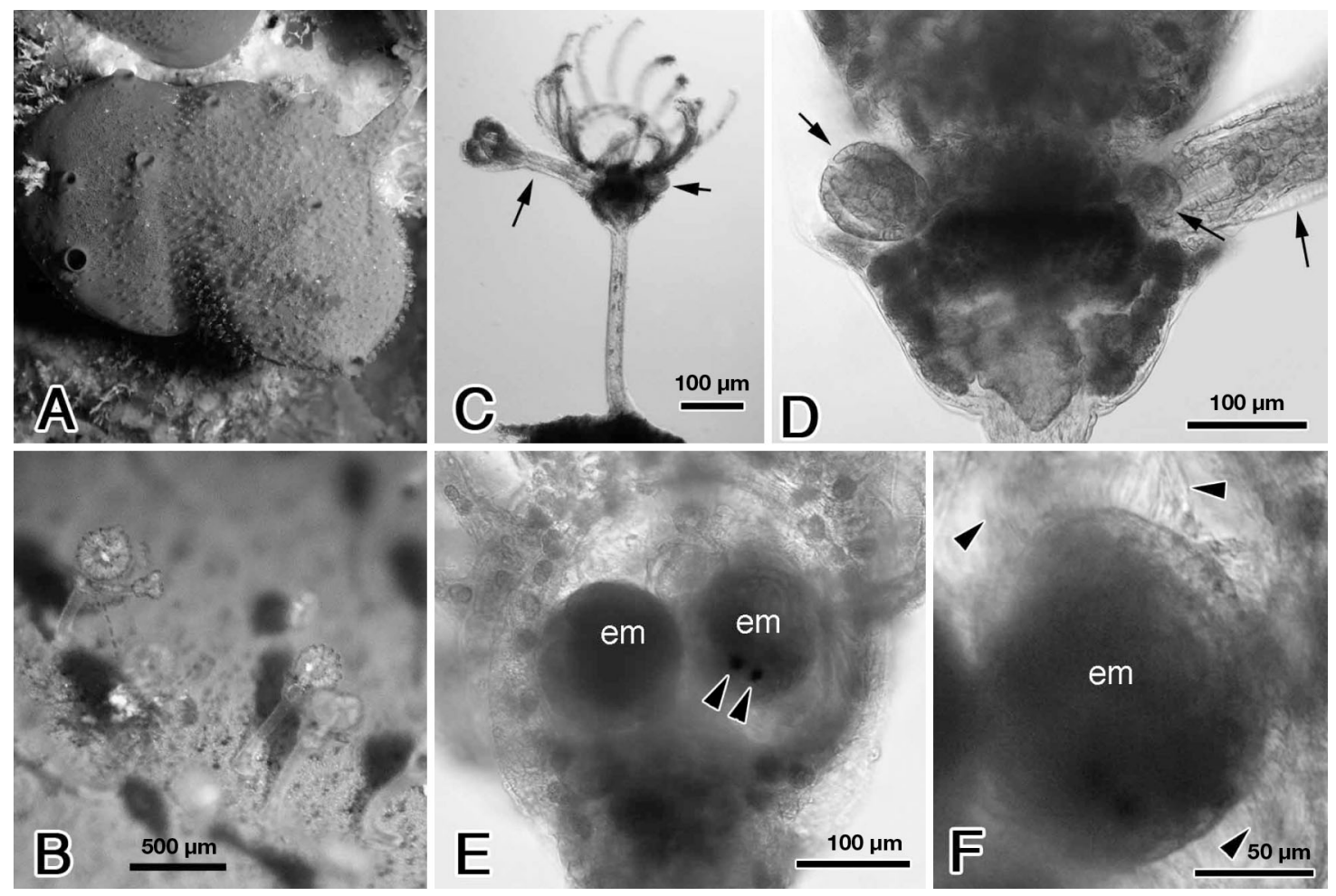

Fig. 1. Loxosomella plakorticola. (A) A sponge (Plakortis sp.) colonised by many individuals (field photo). (B) Individual entoprocts on a sponge (enlarged). (C) Entoproct with full-grown (arrow, left) and early buds (arrow, right) on the calyx. (D) Calyx with 3 buds (arrows) at both sides of lateral budding pocket (frontal view). (E) Calyx with 2 embryos (em); the right embryo has a pair of eye spots (arrowheads). (F) Enlarged embryo (em) with cilia (arrowheads)

sp., while a few other epizoic taxa were present on the sponges. e.g. bryozoans, polychaetes, ascidians, and brittle stars. In any case, L. plakorticola was the dominant epizoon on this sponge.

In Loxosomella plakorticola, buds were formed in paired lateral pockets of the calyx at the upper half of the stomach (Fig. 1C,D) with up to 4 buds at a time. At the early stage, buds were globular swellings, $\sim 20 \mu \mathrm{m}$ in diameter. Grown buds had the same proportions as adult individuals, and were attached to the parent's calyx by their stalk.

Embryos, 50 to $70 \mu \mathrm{m}$ in diameter, occurred in the atrium of the calyx (Fig. 1E,F). Up to 2 embryos were found on a single parent. Some individuals produced embryos and buds at the same time. The embryos had a pair of eyespots and cilia (Fig. 1E,F).

\section{Fluctuation of sexual and asexual reproduction}

$$
\text { Asexual reproduction (= budding) }
$$

During the 2 yr study period, a total of 2300 individuals was examined for asexual reproduction. Budding was observed all year round. Total number of buds per 100 individuals ranged from 91 (September 2006) to 232 (March 2008) (Fig. 2A). The proportion of budding individuals ranged from $67 \%$ (September 2006) to $98 \%$ (July 2008) with $\leq 4$ buds ind. ${ }^{-1}$ (Fig. 2B). The number of buds on each individual was significantly different among months ( $p<0.0001$, Kruskal-Wallis test), and individuals had significantly more buds in March, May, June, July, and August than in September, October, November, and December ( $p<0.05$, Dunn's multiple comparisons test). So, budding activity was high in spring to early summer (March to August) and low in late summer to winter (September to December).

Water temperature (Fig. 2A) was always $>20.0^{\circ} \mathrm{C}$ during the $2 \mathrm{yr}$ of the study. Temperature ranged from $21.0^{\circ} \mathrm{C}$ in January and February 2007 , and in January 2008 to $29.5^{\circ} \mathrm{C}$ in August 2008. In a crosscorrelation analysis of temperature versus total number of buds in 100 individuals, high correlation values were found at a lag of 1, 2, and 3 mo (Fig. 3A), with a maximum at time lag of 2 mo. This result suggested a significant negative relationship between the numbers of budding individuals and water temperature 2 mo previous to bud formation. Likewise, an analysis of water temper- 


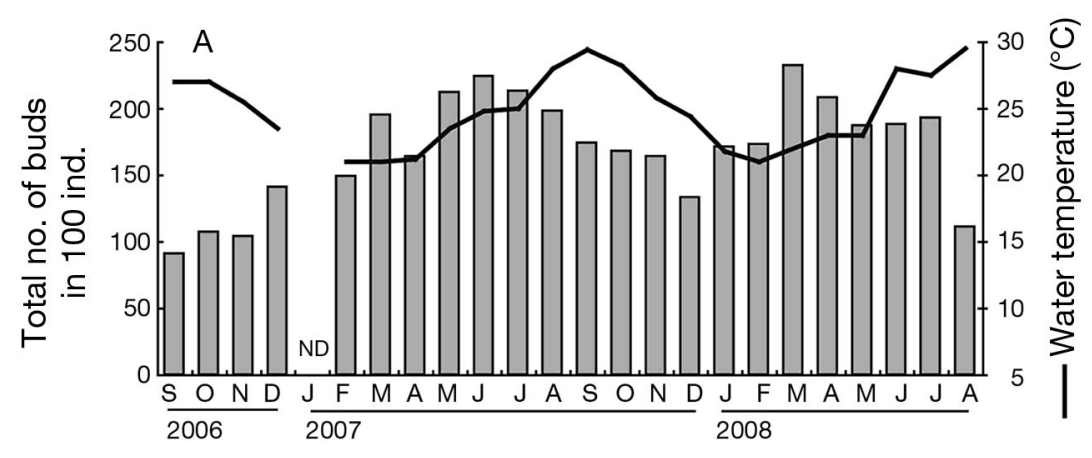

B

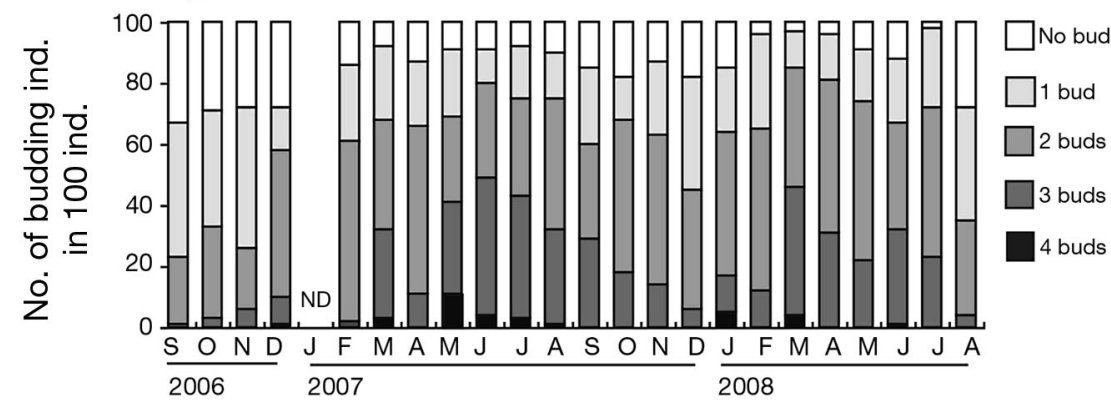

Fig. 2. Loxosomella plakorticola. Monthly fluctuation in asexual reproduction. (A) Total number of buds in 100 individuals and water temperature at the collection site. (B) Number of budding individuals in 100 individuals. Gray shading = number of buds per individual. ND: no data

ature versus number of budding individuals showed that the correlation coefficient was most significant at a time lag of 2 mo (Fig. 3B). This result again suggested that budding activity had a significant negative relationship with temperature 2 mo previously.

\section{Sexual reproduction}

Among the 2300 individuals examined, only 16 individuals $(0.67 \%)$ possessed embryos: 1 in November 2006, 1 in April 2007, and 14 in August 2008 (Fig. 4). Gonads were never observed in our specimens. Some individuals had both embryos and buds: one in April 2007 and 7 in August 2008 (Fig. 4). There were no obvious seasonal patterns in sexual reproduction. Because the incubation period of embryos is unknown in the present species, it is possible that we missed some brooding individuals between observations.

\section{Fluctuation of density and distribution of Loxosomella plakorticola on the sponges}

For 13 to 22 mo, 4 sponges were monitored monthly (Fig. 5). Since these 4 sponges were different in size, the grids of $2 \times 2 \mathrm{~cm}$ are shown at different magnifica- tions for each sponge in Fig. 5. Sponges changed in shape and size by varying degrees during the monitoring period due to growth and regression. The density and distribution of the entoprocts often fluctuated dramatically within a few months (Fig. 5). Sponge \#1 with small patches of entoprocts at low density $\left(<2.5\right.$ ind $\mathrm{cm}^{-2}$ ) was entirely covered with entoprocts 3 mo later (May to August 2008 in Fig. 5). On Sponge \#3, no entoprocts were found though it had been densely covered 2 mo previously (June to August 2007 in Fig. 5).

As an example for fluctuations, the large Sponge \#1 (ca. $20 \times 12 \mathrm{~cm}$ ) and its surface was almost entirely covered with Loxosomella plakorticola at high density ( $>25$ ind $\mathrm{cm}^{-2}$ ) for 2 mo at the beginning of monitoring (October 2006). Then, the density of the entoprocts decreased slightly in December 2006, and most entoprocts disappeared by February 2007. Afterward, no entoprocts were found on the sponge for $4 \mathrm{mo}$ (from March to June 2007). Small numbers of individuals

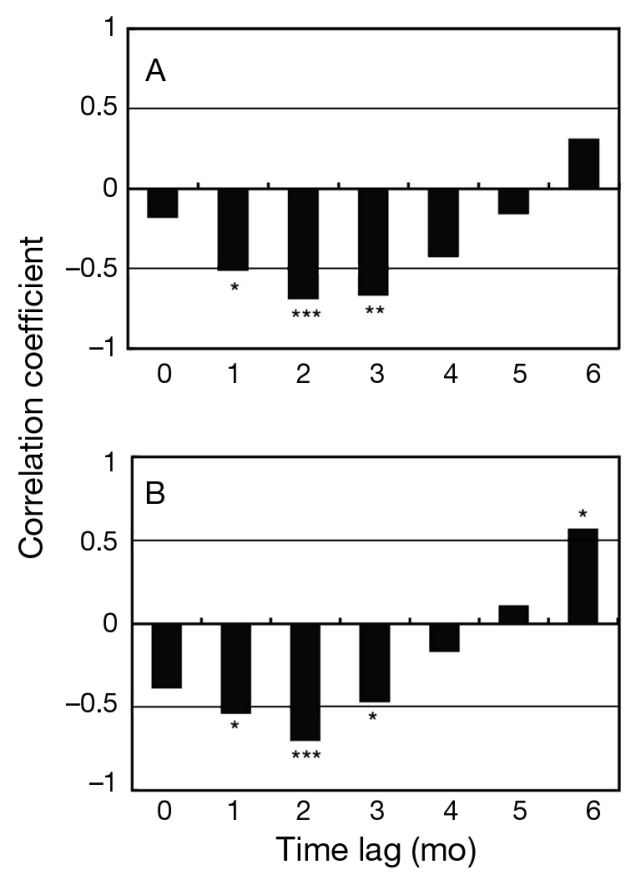

Fig. 3. Loxosomella plakorticola. Cross-correlation analysis between (A) the total number of buds in 100 individuals and water temperature, and (B) the number of budding individuals and water temperature. ${ }^{*} \mathrm{p}<0.5^{*}{ }^{* *} \mathrm{p}<0.1{ }^{* * *} \mathrm{p}<0.01$ 


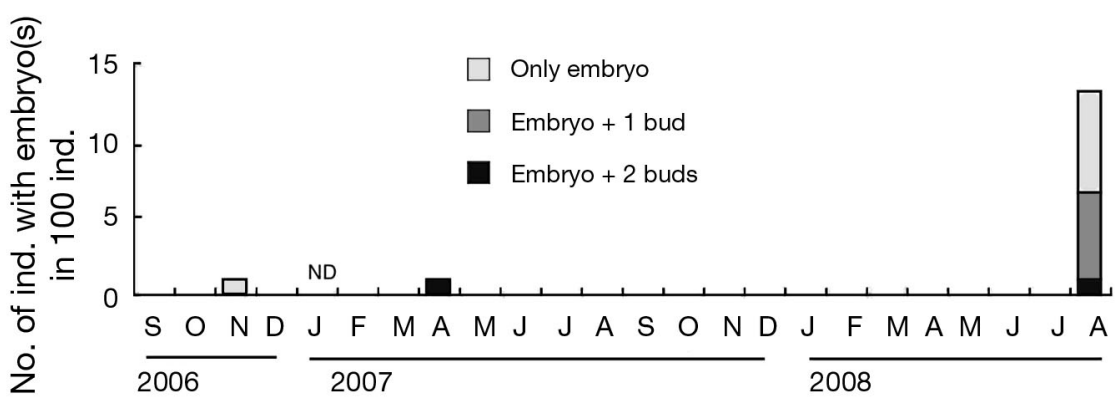

Fig. 4. Loxosomella plakorticola. Number of individuals having embryo(s) in 100 individuals of each month. Gray shading show the number of buds on each individual with embryo(s). ND: no data were not observed in this study. We observed 3 variable sites over $554 \mathrm{bp}$, and detected 4 haplotypes in 40 individuals from the 2 sponges collected at Manza. All variations found in the 4 haplotypes were single nucleotide polymorphisms. We detected 4 haplotypes in 20 individuals of L. plakorticola living on Sponge \#I, while 2 haplotypes were detected from Sponge \#II (Table 2). The 2 haplotypes from Sponge \#II, i.e. $\mathrm{b}$ and $\mathrm{c}$ in Table 2, were the same as 2 of the 4 haplotypes from Sponge \#I.

\section{DISCUSSION}

appeared again in July 2007, but the populations formed small patches on the sponge, and their densities were low $\left(<2.5\right.$ ind. $\left.\mathrm{cm}^{-2}\right)$ until October 2007. The density and distribution of the entoprocts increased from November 2007 to January 2008, and then decreased slowly from January to May 2008. The density and distribution increased again from May to July 2008. At the end of monitoring (August 2008), the entoprocts again entirely covered the sponge at high density (>25 ind. $\mathrm{cm}^{-2}$ ).

In contrast to Sponge \#1, an entoproct population on Sponge \#4 lasted over 13 mo, while the density of the entoprocts showed some fluctuations. The density of entoprocts was high (>25 ind. $\mathrm{cm}^{-2}$ ) for $5 \mathrm{mo}$ from August 2007 to December 2007. The density fluctuated from January to May 2008, and was high again from June to August 2008.

\section{Genetic heterogeneity of entoprocts on the same sponge}

The length of the 18S rDNA region from Loxosomella plakorticla is $\sim 1800 \mathrm{bp}$. As the result of a homology search, the sequence was almost identical to previously reported 18S rDNA sequences of $L$. plakotricola (Accession No. GU125752, Fuchs et al. 2010).

The length of the ITS1 region of Loxosomella plakorticola is $554 \mathrm{bp}$, and deletion or insertion mutations

Table 2. Loxosomella plakorticola. Genetic diversity. N: number of individuals examined; $A$ : number of alleles

\begin{tabular}{|lcccccc|}
\hline \multirow{2}{*}{ Population } & \multirow{2}{*}{$N$} & \multirow{4}{*}{$A$} & \multicolumn{4}{c|}{ Number of ITS1 haplotype } \\
& & & a & b & C & d \\
\hline Sponge \#I & 20 & 4 & 4 & 7 & 6 & 3 \\
Sponge \#II & 20 & 2 & & 10 & 10 & \\
\hline
\end{tabular}

The 2 yr survey revealed seasonal changes of fecundity in year-round budding and the rare occurrence of sexual reproduction in the sponge-inhabiting entoproct Loxosomella plakorticola. Year-round predominance of asexual reproduction is expected to cause cloning of populations, genetic analyses, however, demonstrated that each population consists of multiple haplotypes. Monthly monitoring of 4 sponges showed dynamic fluctuation of their entoproct populations.

To date, 19 entoproct species are known to associate with sponges, and they all belong to the genus Loxosomella. Budding has been observed in all species, while sexual reproduction (presence of gonads and/or embryos) has been recorded only for 9 species: $L$. almugnecarensis, L. ameliae, L. cricketae, L. museriensis, L. pes, L. raja, L. studiosorum, L. tethyae, and L. vivipara (Schmidt 1876, 1878, Toriumi 1951, Nielsen 1966a, b, Bobin 1968, Sánchez-Tocino \& Tierno de Figueroa 2009, Tierno de Figueroa \& Sánchez-Tocino 2009). Since these records do not include annual data, it is unclear whether populations on sponges are controlled seasonally or not. For the colonial entoproct Barentsia discreta, Emschermann (1985) reported that high water temperature $\left(>22^{\circ} \mathrm{C}\right)$ induces sexual maturation in the laboratory. Mukai \& Makioka (1980) studied the same species in the field at Shimoda, Shizuoka, a temperate area of Japan, and reported 'colonies had a maximum fertility in August and September, when the sea temperature was the highest of the year'. For 6 non-commensal, solitary entoproct species grown on glass slides at Okinawa Island, sexual reproduction was exclusively found in July and August. The frequency of individuals having embryos varied from $0.21 \%$ to $38.6 \%$ among species and collection sites (Iseto et al. 2007). Since the seawater temperature reached a maximum $\left(>30^{\circ} \mathrm{C}\right)$ during this period (Iseto et al. 2007), high temperature may induce sexual 

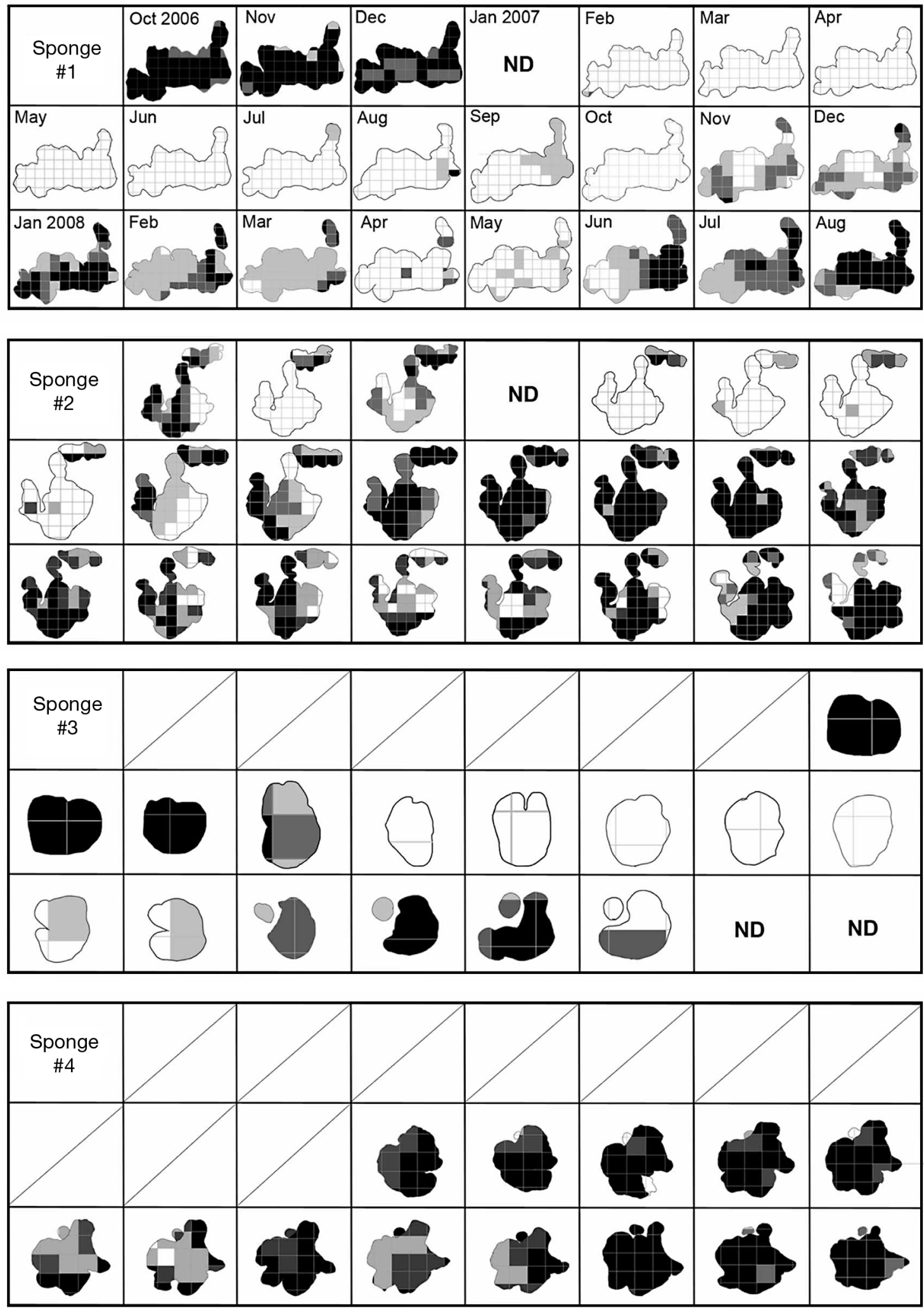

Number of entoprocts in each grid cell: $\square=0 \quad \square<10 \quad \square<100 \square \geq 100$

Fig. 5. Loxosomella plakorticola. Population dynamics on Sponges \#1 to \#4. Gray-shade indicates the number of entoprocts in each $2 \times 2 \mathrm{~cm}$ grid cell. The 4 sponges were different in size and are shown at different magnification. They grew or regressed, changing shape and size during the monitoring period. ND: no data 
reproduction in these entoproct species. In $L$. plakorticola, embryos were found in only $16(0.67 \%)$ out of a total of 2300 examined individuals (100 individuals in each of $23 \mathrm{mo}$ ), and the occurrence showed no seasonal pattern (see Fig. 4). Thus our results suggest that water temperature is not the only factor controlling sexual reproduction in solitary entoprocts.

In contrast to sexual reproduction, budding occurred all year round in Loxosomella plakorticola and the proportion of budding individuals ranged from $67 \%$ (September 2006) to $98 \%$ (July 2008). Budding is probably the principal mode of proliferation in solitary entoprocts, and has been reported for many solitary species to occur throughout the year (Mariscal 1975, Nielsen 1989, Iseto et al. 2007). Solitary entoprocts generally possess several buds at once, and L. plakorticola has a maximum of 4 buds. The number of buds per individual was highest in March to July and lowest in August to December, indicating seasonality of budding in this species. Nielsen (1989) noted that budding is much more active from summer to autumn in 3 European entoprocts, Loxosoma pectinaricola, L. rhodinicola, and Loxosomella harmeri. Iseto et al. (2007) reported that active budding occurred in summer in some noncommensal species on coral reefs at Okinawa Island, i.e. Loxomitra mizugamaensis, L. tetraorganon, Loxosomella aloxiata, L. intragemmata, L. lecythifera, and L. monocera. As such, active budding seems to correlate with high seawater temperatures. This study, however, indicated that high seawater temperature does not always stimulate budding activity: the number of buds in L. plakorticola correlated negatively with the water temperature 2 to 3 mo previously (Fig. 3). Because there were time lags between water temperature and budding activity, temperature is an unlikely factor for directly controlling budding activity and unknown factor(s) related to the water temperature probably affect budding. Bobin \& Prenant (1954) suggested that bud numbers of solitary entoprocts are influenced by nutrition. Potential food biomass is unknown at the present study site. Chlorophyll $a$ and nutrient concentration in coral reef water, however, are low almost year-round off Sesoko Island, which is located near the present study site (Tada et al. 2003), suggesting that food supply is not a primary factor controlling the seasonal fluctuation of fecundity in $L$. plakorticola. The factor(s) that principally control budding activity remain unknown so far.

This is the first long-term monitoring of entoproct populations in their natural habitat. Prior to the present study, 2 studies using settlement panels had reported seasonal change in the abundance of solitary entoprocts. Ryland \& Austin (1960) reported that 2 solitary entoproct species appeared on tufnol panels immersed in a dock at Swansea, South Wales. Loxomitra kefer- steinii was recorded on the panel from July to December with a peak in September and October, and Loxosomella antedonis from January to July with a peak in May. Iseto et al. (2007) reported seasonal change in abundance of 9 solitary entoproct species grown on glass slides that had been submerged for 2 mo in shallow water off Okinawa Island. The abundance was high in summer and low in winter, and active budding resulted in the formation of large populations in summer. In contrast to these 2 studies using experimental settlement panels, the present study showed that entoproct populations on sponges fluctuated without any seasonal pattern (see Fig. 5).

Loxosomella plakorticola sometimes disappeared from their sponge within 1 to 2 mo regardless of season. This does not mean they do not proliferate during these periods because our monthly surveys indicated that they always produced buds. Several possible factors may cause disappearance of L. plakorticola populations, such as predation, aging, or massdetachment from their sponges. Turbellarians and nudibranchs predate on entoprocts (Canning \& Carlton 2000, Sánchez-Tocino \& Cervera 2006) and the density of the sponge-inhabiting Loxosomella ameliae, was reported to be affected by the feeding of Trapania seaslugs (Sánchez-Tocino \& Cervera 2006). Predators possibly cause the loxosomatids to escape by detachment, resulting in rapid disappearance. Although we could not find any predators on the sponges, unknown predator(s) possibly exist and affect the population of L. plakorticola. Unfavorable changes of the microenvironment on the host sponge may result in massdetachment of the entoprocts. This hypothesis requires the presumption that the microenvironment may recover quickly because reduced populations sometimes recovered within a few months (e.g. Sponge \#1, November 2007; Sponge \#3 January 2008; Fig. 5). However, we could not find any deterioration or rapid environmental changes around the 4 sponges monitored, and thus the microenvironment of the host sponge appeared to be stable and not cause the fluctuation of the entoproct populations. Disappearance by aging is improbable as young individuals are always supplied to the population by budding. In conclusion, we assume that the mass disappearance was mainly caused by predation or mass-detachment to avoid predators.

After abrupt disappearance, populations of Loxosomella plakorticola often recovered on the same sponge. If 1 recruit settles on a sponge and propogates only by budding, the population will be comprised of clone individuals. However, our genetic analysis demonstrated that the individuals on the same sponge included several haplotypes, indicating that the population is comprised of multiple clones. Thus the rapid growth of the population was attained not only by bud- 
ding from a single recruit but also by recruitment from other populations. The trochophore-like larvae do not seem to contribute much to the usual recruitment because sexual reproduction appeared to be rare in the present study. Liberated buds of solitary entoprocts can swim using their ciliated tentacles (Ryland \& Austin 1960). Since budding was active all year round in the present species, liberated buds are the most plausible recruits to the sponges. Konno (1972) collected Loxosomella bifida adults with a plankton-net at Fukaura, Aomori, Japan, which had detached from their host polychaetes and drifted in the water. Adult $L$. plakorticola may disperse in a similar way. Adults of many Loxosomella species are known to glide over the substratum using their basal foot, and this is another possible way of recruitment of L. plakorticola between the populations. However, the foot of the present species is specialized to attach to the sponge surface (Iseto et al. 2008, Iseto \& Hirose 2010) and seems unsuitable for moving between sponges.

According to Iseto et al. (2007), solitary entoprocts dominated on glass slides submerged for $2 \mathrm{mo}$, while other organisms (e.g. ciliates, bryozoans, ascidians, sponges, and colonial entoprocts) occasionally occurred. However, the number of solitary entoprocts on the glass slides decreased in longer assessments due to fouling by larger sessile organisms ( $T$. Iseto pers. obs.). In contrast to the entoproct populations on the settlement panels, Loxosomella plakorticola sometimes maintained their population for longer periods on sponges (see Sponges \#2 and \#4 in Fig. 5), while the densities of the entoprocts were unstable. Other benthos were observed to rarely inhabit the sponges, probably due to the chemical defense(s) of the sponges. Many cytotoxic and antifouling compounds have been isolated from Plakortis species (e.g. Kossuga et al. 2008, Bowling et al. 2010). Therefore, L. plakorticola is supposed to be tolerant to the chemical defense(s) of the host and the absence of competitors for the habitat probably enables the stable survival of the entoprocts. Moreover, many potential predators are likely repelled by the sponge's chemical defense(s), further enabling the stable survival of the sponge and its commensal.

As described above, the reproduction of Loxosomella plakorticola is characterized by year-round budding with seasonal fluctuation, rare occurrence of embryos regardless of season, and simultaneous occurrence of buds and embryos on the same individuals. Hughes \& Cancino (1985) reviewed the alternate sexual and asexual reproduction in many invertebrates. For instance, the annual peaks of the 2 modes of reproduction occur at different times of the year in intertidal sea anemones, Anthopleura elegantissima and A. xanthogrammica, and also in a brittle star, Ophaiactis savignyi (see Sebens 1981, 1982, McGovern 2002). The occurrence of self-division is much lower in the breeding season in the starfish Coscinasterias tenuispina (see Crozier 1920). On the other hand, in the sea cucumbers Holothuria atra and $H$. edulis, similar to $L$. plakorticola, the cycles of asexual/sexual reproduction seem uncorrelated and some asexually reproducing individuals are sexually mature (see Uthicke 1997). Interestingly, sexual reproduction appeared unsuccessful but asexual reproduction occurred throughout the year in the populations of $H$. atra on intertidal flats in South Taiwan (Chao et al. 1993), suggesting intraspecific plasticity of the reproductive patterns responding to the habitat environment. As the occurrence of sexual reproduction of $L$. plakorticola was rare in the populations studied here, possible plasticity of reproductive patterns suggests that sexual reproduction is active in other populations at other places.

In general, clonal animals are more successful than aclonal animals in stable environments (Jackson 1985), and the year-round predominance of asexual reproduction in Loxosomella plakorticola may indicate the environmental stability of their habitat. Since the present species inhabit a specific host sponge, Plakortis sp., the microenvironments of the habitat are expected to be stable and less variable among the populations. However, this idea may conflict with the dynamic change of the populations on the sponges. Many liberated buds probably did not only settle on the same sponge of the parent individuals but also dispersed to settle on other sponges. It is reasonable for L. plakorticola to actively produce buds and broadcast them so as to find new habitats for settlement because its host sponge Plakortis sp. is sporadically distributed and not always common in the coral reefs. In contrast, the importance of sexual reproduction was unremarkable in the present study, because few individuals were shown to have embryos. In L. plakorticola, larvae are possibly indispensable only to maintain genetic heterogeneity and/or to disperse over very far distances. It is uncertain whether the rare occurrence of sexual reproduction is common in other sponge-inhabiting entoprocts and other sessile meiobenthos. A comparative survey is necessary to verify the generality of this reproductive strategy.

Acknowledgements. This study was partly supported by the Fujiwara Natural History Foundation (no. 2006-14 to T.I., no. 2009-17 to M.H.). We thank Dr. J. D. Reimer (University of the Ryukyus) for critical reading of the manuscript.

\section{LITERATURE CITED}

Atkins D (1932) Loxosomatidae of the Plymouth Area, including L. obesum sp. nov. Q J Microsc Sci 75:321-391

Bobin G (1968) Loxosomella museriensis n. sp. Entoprocte Loxosomatidae de Mer Rouge. Isr J Zool 17:175-189 
Bobin G, Prenant M (1954) Étude critique des principaux caractères utilisables dans la classification Loxosomatidae. Ann Sci Nat Sér 11 16:7-33

Bowling JJ, Mohammed R, Diers JA, Hamann MT (2010) Abundant ketone isolated from oily Plakortis sponge demonstrates antifouling properties. Chemoecology doi: 10.1007/s00049-010-0049-z

Canning MH, Carlton JT (2000) Predation on kamptozoans (Entoprocta). Invertebr Biol 119:386-387

Chao SM, Chen CP, Alexander PS (1993) Fission and its effect on population structure of Holothuria atra (Echinodermata: Holothuroidea) in Taiwan. Mar Biol 116:109-115

Crozier WJ (1920) Notes on some problems of adaptation. 2. On the temporal relations of asexual propagation and gametic reproduction in Coscinasterias tenuispina: with a note on direction of progression and on the significance of the madreporites. Biol Bull 39:116-129

Emschermann P (1985) Factors inducing sexual maturation and influencing the sex determination of Barentsia discreta Busk (Entoprocta, Barentsiidae). In: Nielsen C, Larwood GP (eds) Bryozoa: Ordovician to recent. Olsen and Olsen, Fredensborg, p 101-108

Fuchs J, Iseto T, Hirose M, Sundberg P, Obst M (2010) The first internal molecular phylogeny of the animal phylum Entoprocta (Kamptozoa). Mol Phylogenet Evol 56:370-379

Hughes RN, Cancino JM (1985) An ecological overview of cloning in Metazoa. In: Jackson JBC, Buss LW, Cook RE (eds) Population biology and evolution of clonal organisms. Yale Univ Press, New Haven, CT, p 153-186

Iseto T (2002) Loxocorone, a new genus of the family Loxosomatidae (Entoprocta: Solitaria), with descriptions of two new Loxomitra (sensu stricto) and a new Loxocorone from Okinawa, the Ryukyu Archipelago, Japan. Zool Sci 19: 359-367

Iseto T (2005) A review of non-commensal Loxosomatids: collection, culture, and taxonomy, with new implications to the benefit of commensalism (Entoprocta: Loxosomatidae). In: Moyano Gl, Cancino JM, Jackson PNW (eds) Bryozoan studies 2004. Taylor \& Francis, London, p 133-140

Iseto T, Hirose E (2010) Comparative morphology of the foot structure of four genera of Loxosomatidae (Entoprocta), implications for foot functions and taxonomy. J Morphol 271:1185-1196

Iseto T, Yokuta Y, Hirose E (2007) Seasonal change of species composition, abundance, and reproduction of solitary entoprocts in Okinawa Island, the Ryukyu Archipelago, Japan. Mar Biol 151:2099-2107

Iseto T, Sugiyama N, Hirose E (2008) A new sponge-inhabiting Loxosomella (Entoprocta: Loxosomatidae) from Okinawa Island, Japan, with special focus on foot structure. Zoolog Sci 25:1171-1178

Jackson JBC (1985) Distribution and ecology of clonal aclonal benthic invertebrates. In: Jackson JBC, Buss LW, Cook RE (eds) Population biology and evolution of clonal organisms. Yale Univ Press, New Haven, CT, p 297-355

Konno K (1972) Studies on Japanese Entoprocta I. On four new species of Loxosomatids found at Fukaura, Aomori Prefecture. Sci Rep Hirosaki Univ 19:64-78

Kossuga MH, Nascimento AM, Reimao JQ, Tempone AG and others (2008) Antiparasitic, antineuroinflammatory, and cytotoxic polyketides from the marine sponge Plakortis angulospiculatus collected in Brazil. J Nat Prod 71: 334-339

Mariscal RN (1975) Entoprocta. In: Giese AC, Pearse JS (eds)

Editorial responsibility: Charles Birkeland,

Honolulu, Hawaii, USA
Reproduction of marine invertebrates, Vol 2. Academic, New York, NY, p 1-41

McGovern TM (2002) Patterns of sexual and asexual reproduction in the brittle star Ophiactis savignyi in the Florida Keys. Mar Ecol Prog Ser 230:119-126

Mukai H, Makioka T (1980) Some observations on the sex differentiation of an entoproct, Barentsia discreta (Busk). J Exp Zool 213:45-59

Nielsen C (1964) Studies on Danish Entoprocta. Ophelia 1: $1-76$

Nielsen C (1966a) On the life-cycle of some Loxosomatidae (Entoprocta). Ophelia 3:221-247

Nielsen C (1966b) Some Loxosomatidae (Entoprocta) from the Atlantic coast of the United States. Ophelia 3:249-275

Nielsen C (1971) Entoproct life-cycles and the entoproct/ ectoproct relationship. Ophelia 9:209-341

Nielsen C (1989) Entoprocts. Synop Br Fauna New Ser 41: $1-131$

Rowan R, Powers DA (1991) A molecular genetic classification of zooxanthellae and the evolution of animal-algal symbioses. Science 251:1348-1351

Ryland JS, Austin AP (1960) Three species of Kamptozoa new to Britain. Proc Zool Soc Lond 133:423-433

Sánchez-Tocino L, Cervera JL (2006) Primeros datos sobre la dieta de Trapania maculata Haefelfinger, 1960 y Trapania hispalensis Cervera y García-Gómez, 1989 (Mollusca: Nudibranchia). Zool Baetica 17:85-89

Sánchez-Tocino L, Tierno de Figueroa JM (2009) Contribution to the knowledge of the genus Loxosomella (Entoprocta) from the Spanish Mediterranean Sea, with the description of a new species, Loxosomella ameliae sp. nov. Mar Biol Res 5:404-407

Schmidt O (1876) Die Gattung Loxosoma. Archiv Mikroskop Anat 12:1-14

Schmidt O (1878) Bemerkungen zu den Arbeiten über Loxosoma. Z Wiss Zool Abt A 31:68-80

Sebens KP (1981) Reproductive ecology of the intertidal sea anemones Anthopleura xanthogrammica (Brandt) and $A$. elegantissima (Brandt): Body size, habitat, and sexual reproduction. J Exp Mar Biol Ecol 54:225-250

Sebens KP (1982) Asexual reproduction in Anthopleura elegantissima (Anthozoa: Actinaria): Seasonality and spatial extent of clones. Ecology 63:434-444

Tada K, Sakai N, Nakano Y, Takemura A, Montani S (2003) Size-fractionated phytoplankton biomass in coral reef waters off Sesoko Island, Okinawa, Japan. J Plankton Res 25:991-997

Tierno de Figueroa JM, Sánchez-Tocino L (2009) Loxosomella almugnecarensis n. sp. (Entoprocta: Loxosomatidae) -a new sponge epizoite from the Iberian Mediterranean Sea. Zootaxa 2236:65-68

Toriumi M (1951) Some entoprocts found in Matsushima Bay. Sci Rep Tohoku Univ 4 Ser Biol 19:17-22

Uthicke S (1997) Seasonality of asexual reproduction in Holothuria (Halodeima) atra, H. (H.) edulis and Stichopus chloronotus (Holothuroidea: Aspidochirotida) on the Great Barrier Reef. Mar Biol 129:435-441

Wasson K (1997) Sexual modes in the colonial Kamptozoan genus Barentsia. Biol Bull 193:163-170

White TJ, Burns T, Lee S, Tayor J (1990) Amplification and direct sequencing of fungal ribosomal RNA genes for phylogenetics. In: Innis MA, Gelfand DH, Sninsky JJ, White TJ (eds) PCR protocols, a guide to methods and applications. Academic Press, San Diego, CA, p 315-322

Submitted: June 7, 2010; Accepted: July 24, 2010

Proofs received from author(s): September 19, 2010 